\title{
3-D Modeling of Temperature Effect on a Polycrystalline Silicon Solar Cell under Intense Light Illumination
}

\author{
Boubacar Soro, Martial Zoungrana*, Issa Zerbo, Mahamadi Savadogo, \\ Dieudonné Joseph Bathiebo
}

Laboratory of Thermal and Renewable Energies, Department of Physics, Unit of Training and Research in Pure and Applied Sciences, University Ouaga I Prof Joseph KI-ZERBO, Ouagadougou, Burkina Faso

Email: *zmartial2003@yahoo.fr

How to cite this paper: Soro, B., Zoungrana, M., Zerbo, I., Savadogo, M. and Bathiebo, D.J. (2017) 3-D Modeling of Temperature Effect on a Polycrystalline Silicon Solar Cell under Intense Light Illumination. Smart Grid and Renewable Energy, 8, 291-304.

https://doi.org/10.4236/sgre.2017.89019

Received: July 20, 2017

Accepted: August 27, 2017

Published: August 30, 2017

Copyright (c) 2017 by authors and Scientific Research Publishing Inc. This work is licensed under the Creative Commons Attribution International License (CC BY 4.0).

http://creativecommons.org/licenses/by/4.0/

(c) (i) Open Access

\begin{abstract}
The efficiency of a silicon solar cell is directly linked to the quantity of carrier photogenerated in its base. It increases with the increase of the quantity of carrier in the base of the solar cell. The carrier density in the base of the solar cell increases with the increase of the flux of photons that crosses the solar cell. One of the methods used to increase the flux of photon on the illuminated side of the solar cell is the intensification of the illumination light. However, the intensification of the light come with the increase of the energy released by thermalization, the collision between carriers, their braking due to the carriers concentration gradient electric field which lead to increase the temperature in the base of the solar cell. This work presents a 3-D study, of the effect of the temperature on the electronic parameters of a polycrystalline silicon solar under intense light illumination. The electronic parameters on which we analyze the temperature effect are: the mobility of solar cell carriers (electrons and holes), their diffusion coefficient, their diffusion length and their distribution in the bulk of the base. To study the effect of the temperature on electronic parameters, we take into account, the dependence of carriers (electrons and holes) mobility with the temperature $\left(\mu_{n}(\mathrm{~T}) \mu_{p}(\mathrm{~T})\right)$. Then, the resolution of the continuity equation, which is a function of the carriers gradient electric field and the carriers mobility, leads to the expressions of the diffusion coefficient, the diffusion length, and the density of carriers which are function of the temperature. Then, we studied the effects of the temperature on the diffusion parameters in order to explain their effect on the behavior the carriers distribution in intermediate, short circuit and open circuit operating modes at several positions in the base depth. It appears through this study that the diffusion coefficient and the diffusion length decrease with the increase of
\end{abstract}


the temperature. We observe also that with the increase of the temperature, the density of carriers in the base of the solar cell in short circuit and open voltage operating modes increases. In intermediate operating mode, the density of carriers increases also with the temperature but it is function of the base depth.

\section{Keywords}

Intense Light, Electric Field, Temperature, Diffusion Coefficient, Diffusion Length, Density of Carriers

\section{Introduction}

The efficiency of a solar cell is directly linked to the density of carriers in the base of the solar cell which is a function of the support material band gap of this solar cell, the illumination mode, the carriers diffusion parameters and recombination parameters. Several analytical and experimental studies have been done in monochromatic [1] [2] and multispectral [3] [4] [5] [6] [7] illuminations. Some studies have also been done on light illumination effects on monofacial [2] [3] [5] [6], bifacial [1] [4] [6] [7] [8] and amorphous [8] solar cells. It appears through these studies that the increase of illumination power comes with an increase of the density of carriers in the base of the solar cell [9] [10]. Some studies put also in evidence that external parameters such as magnetic field [10] [11] electric field [11] [12], light concentration [10] [13] can influence the diffusion coefficient of a silicon solar cell.

Even though the increase of the intensity of the light illumination leads to an increase of the carrier photogenaration and then to an increase of the density of carriers in the base [10], this situation generates an increase of the temperature in the base of the solar cell [14] [15] [16]. In experimental studies [14] [17] [18], it was proved that the short circuit current and the conversion efficiency increases with the increase of the temperature when the open circuit voltage decreases. An experimental study proved, that the temperature influences the band gaps of GaAs, GaP, Ge, Si and C solar cells [19]. It appears through this study that the band gaps of all of these semiconductors decreases with the increase of the temperature.

In previous works [10] [20], the effect of the light intensity on the performance of a silicon solar cell has been studied. It was proved in these studies that, the increase of the intensity of the illumination light leads to the increase of the density of carriers density in the base of the solar cell, an increase of the short circuit current, an increase of the electric power and the conversion efficiency [10]. The increase of the light intensity leads none the less to an increase of the quantity of the energy released by thermalization in the base of the solar cell, but also, to an increase of the collision of the carriers in the base of the solar cell. Another phenomenon which appears with the intense photogeneration in the 
base due to the intensification of the illumination light is the apparition of the carriers gradient electric field. Due to its orientation, the carriers gradient electric field is opposed to the carriers movement toward the junction of the solar cell, and then that will has as effect to brake them. The energy released by thermalization, by collision and by braking in the base of the solar cell leads to heat it, and then to increase the temperature in it. In the present work, we study none the less the physical phenomena which leads to the increase of the temperature in the base of the solar but also the effects of the temperature on the carriers mobility, the diffusion coefficient, the diffusion length and carriers density of a polycrystalline silicon solar cell.

\section{Model and Assumptions}

\subsection{Analytical Formulation}

In this work, we propose a three-dimensional (3D) study of a polycrystalline silicon solar cell (n-p-p $\mathrm{p}^{+}$operating under an intense multispectral light. The polycrystalline silicon solar cell is made up of several grains with different sizes and forms separated by grain boundaries [21] [22] [23] which are recombination centers. In our study model, each grain has a square section $\left(g_{\mathrm{x}}=g_{y}\right)$ and a thickness $H$ as shown in Figure 1 [21] [22].

The recombination planes are assumed to be thin surfaces between two adjacent grains and are located at $x= \pm \frac{g_{x}}{2}$ and $y= \pm \frac{g_{y}}{2}$, respectively perpendicular to the $\mathrm{x}$ and $\mathrm{y}$ axis of cartesian coordinates $(O, x, y, z)$ [21] [22] [23]. The grain boundaries are perpendicular to the junction and their recombination velocity $S_{g b}$ is constant.

The polycrystalline silicon solar cell is illuminated by an intense light concentration ( $C>50$ suns), and then due to the intense photogeneration in the base of

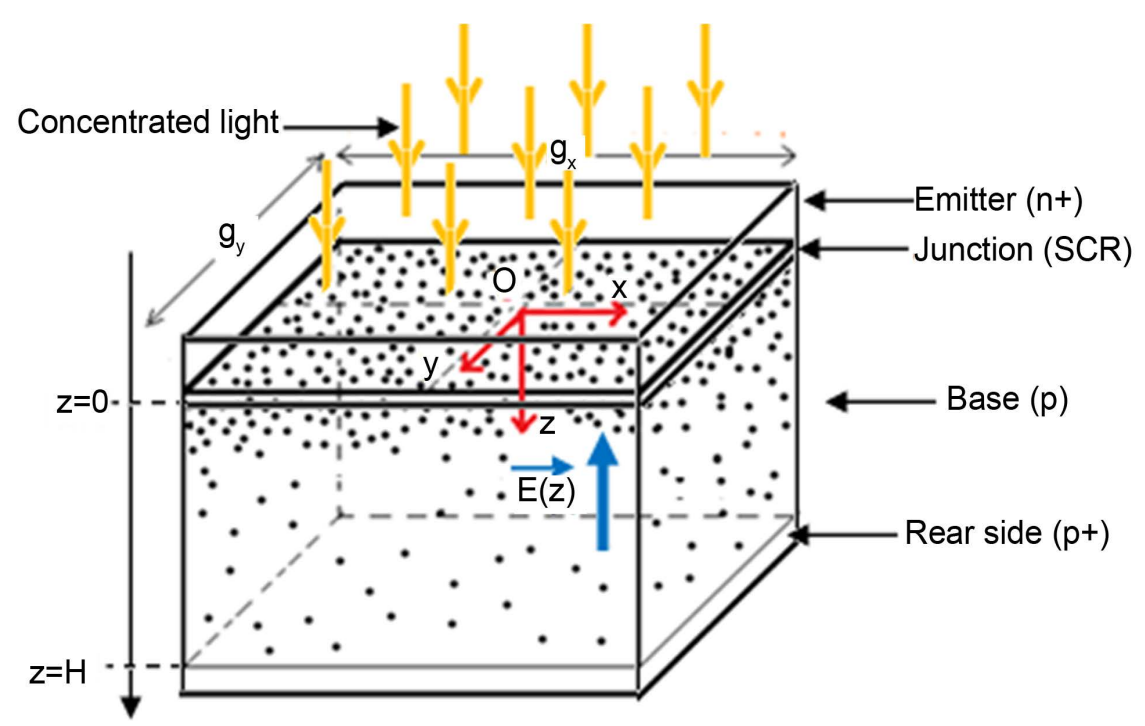

Figure 1. Grain of a polycrystalline solar cell under an intense light illumination. 
the solar cell for this kind of illumination, we take into account the electric field due to the carriers concentration gradient in the base [13] [21] given by Equation (1):

$$
E(z)=\frac{D_{p}-D_{n}}{\mu_{p}(T)+\mu_{n}(T)} \cdot \frac{1}{\delta(x, y, z)} \cdot \frac{\partial \delta(x, y, z)}{\partial z}
$$

In this expressions: $D_{n}$ and $D_{p}$ are respectively electrons and holes diffusion coefficients, $\mu_{n}(T)$ and $\mu_{p}(T)$ are electrons and holes mobility depending on the temperature and $\delta(x)$ is the density of excess minority carrier in the base of the illuminated solar cell.

The contribution of the emitter is not taken into account and we work in the theory of the quasi-neutral base (QNB) [4] [12] [13].

\subsection{Determination and Resolution of the Continuity Equation}

Under the intense light illumination, the total current $\boldsymbol{J}_{n}$ resulting of the movement of the carriers photo generated in the solar cell is the sum of two kinds of currents:

- the diffusion current $\boldsymbol{J}_{d}=e D_{n} \nabla \delta(x, y, z)$ resulting of carriers diffusion along $x, y, z$ axis

- the conduction current $\boldsymbol{J}_{c}=e \mu_{n}(T) \delta(x, y, z) \boldsymbol{E}(z)$ related to the taking into account of the electric field due to the carriers gradient concentration. The expression of the total current is then given by Equation (2):

$$
\boldsymbol{J}_{n}=\boldsymbol{J}_{d}+\boldsymbol{J}_{c}=e D_{n} \nabla \delta(x, y, z)+e \mu_{n}(T) \delta(x, y, z) \boldsymbol{E}(z)
$$

In Equation (2) the expression of the electric field given by Equation (1) is function of the electrons and holes mobility. The expressions of these mobilities are in turn functions of the temperature of the solar cell and they are expressed by Equation (3):

$$
\mu_{n}(T)=\mu_{0 n}\left(\frac{T}{T_{0}}\right)^{-1.5} \text { et } \mu_{p}(T)=\mu_{0 p}\left(\frac{T}{T_{0}}\right)^{-1.5}
$$

with $\mu_{0 n}=1500 \mathrm{~cm}^{2} \cdot \mathrm{V}^{-1} \cdot \mathrm{s}^{-1}, \mu_{0 p}=475 \mathrm{~cm}^{2} \cdot \mathrm{V}^{-1} \cdot \mathrm{s}^{-1}$ and $T_{0}=300 \mathrm{~K}$.

Taking into account the carriers photogeneration, their diffusion and recombination in the base of the solar cell, the expression, in steady state, of the carriers distribution in the base (p) of the solar cell is given by Equation (4) [2] [7] [10] [12]:

$$
\begin{gathered}
\frac{1}{e} \cdot \nabla \cdot \boldsymbol{J}_{n}+G(z)-R(z)=0 \\
G(z)=C \cdot \sum_{i=1}^{3} a_{i} \mathrm{e}^{-b_{i} z} \text { and } R(z)=\frac{\delta(x, y, z)}{\tau_{n}} \text { are respectively the carriers }
\end{gathered}
$$
generation rate and their recombination rate at a position $z$.

Introducing the expressions of the total current $\boldsymbol{J}_{n}$, the carriers generation rate $G(z)$ and their recombination rate $R(z)$ in Equation (4) and solving it leads to the expression of the continuity equation given by Equation (5) [7] [10] 
[20]:

$$
C_{x} \frac{\partial^{2} \delta(x, y, z, T)}{\partial x^{2}}+C_{y} \frac{\partial^{2} \delta(x, y, z, T)}{\partial y^{2}}+\frac{\partial^{2} \delta(x, y, z, T)}{\partial z^{2}}+\frac{G(z)}{D^{*}}-\frac{\delta(x, y, z, T)}{L^{* 2}}=0
$$

with:

$$
\begin{gathered}
C_{x}=\frac{D_{n}\left(\mu_{p}(T)+\mu_{n}(T)\right)}{2 D_{n} \mu_{n}(T)+D_{n} \mu_{p}(T)-\mu_{n}(T) D_{p}} \\
\text { and } C_{y}=\frac{D_{n}\left(\mu_{p}(T)+\mu_{n}(T)\right)\left(1+\mu_{n}(T)^{2}\right)}{2 D_{n} \mu_{n}(T)+D_{n} \mu_{p}(T)-\mu_{n}(T) D_{p}} \\
D^{*}(T)=\frac{2 D_{n} \mu_{n}(T)+D_{n} \mu_{p}(T)-\mu_{n}(T) D_{p}}{\left(\mu_{p}(T)+\mu_{n}(T)\right)} \text { and } L(T)^{* 2}=D^{*}(T) \tau
\end{gathered}
$$

$D^{*}(T)$ and $L^{*}(T)$ are respectively the carriers diffusion coefficient and diffusion length and they are functions of mobility of carriers which are in turn functions of the temperature.

The general shape of the solution of the partial derivative differential Equation (5) is given by Equation (8) [22] [23]:

$$
\delta(x, y, z, T)=\sum_{j} \sum_{k} Z_{j k}(z) \cdot \cos \left(C_{x j} \cdot x\right) \cdot \cos \left(C_{y k} \cdot y\right)
$$

with

$$
C_{x j}=\frac{C_{j}}{\sqrt{C_{x}}} \text { and } C_{y k}=\frac{C_{k}}{\sqrt{C_{y}}}
$$

In Equation (8), the expression of $Z_{j k}(z)$ can be found using the orthogonality conditions of the functions $\cos \left(C_{x j} x\right)$ and $\cos \left(C_{y k} y\right)$ and the grain boundary conditions given by Equation (10):

$$
\begin{aligned}
& {\left[\frac{\partial \delta(x, y, z, T)}{\partial x}\right]_{x= \pm \frac{g_{x}}{2}}= \pm \frac{S_{g b}}{D^{*}} \delta\left( \pm \frac{g_{x}}{2}, y, z, T\right)} \\
& \text { and }\left[\frac{\partial \delta(x, y, z, T)}{\partial y}\right]_{y= \pm \frac{g_{y}}{2}}= \pm \frac{S_{g b}}{D^{*}} \delta\left(x, \pm \frac{g_{y}}{2}, z, T\right)
\end{aligned}
$$

The expression of $Z_{j k}(z)$ in these conditions is:

$$
Z_{j k}(z)=A_{j k} \cosh \left(\frac{z}{L_{j k}}\right)+B_{j k} \sinh \left(\frac{z}{L_{j k}}\right)-\sum_{i=1}^{3} K_{i} \mathrm{e}^{-b_{i} z}
$$

with:

$$
\begin{gathered}
K_{i}=C \frac{a_{i} L_{j k}^{2}}{D_{j k}\left[\left(b_{i} L_{j k}\right)^{2}-1\right]} \\
\frac{1}{L_{j k}}=\left[C_{j}^{2}+C_{k}^{2}+\frac{1}{L^{* 2}}\right]^{\frac{1}{2}}
\end{gathered}
$$




$$
\frac{1}{D_{j k}}=\frac{16 \sin \left(C_{x j} \cdot \frac{g_{x}}{2}\right) \cdot \sin \left(C_{y k} \cdot \frac{g_{y}}{2}\right)}{D^{*}\left[\sin \left(C_{x j} \cdot g_{x}\right)+C_{x j} \cdot g_{x}\right]\left[\sin \left(C_{y k} \cdot g_{y}\right)+C_{y k} \cdot g_{y}\right]}
$$

The coefficients $A_{j k}$ and $B_{j k}$ are determined trough the boundary conditions at the junction $(z=0)$ and at the rear side at the position $(z=H)$ given by Equation (15):

$$
\begin{aligned}
& D^{*}\left[\frac{\partial \delta(x, y, z, T)}{\partial z}\right]_{z=0}=S_{f} \delta(x, y, 0, T) \\
& \text { and } D^{*}\left[\frac{\partial \delta(x, y, z, T)}{\partial z}\right]_{z=H}=-S_{b} \cdot \delta(x, y, H, T)
\end{aligned}
$$

The expressions of the coefficients $A_{j k}$ et $B_{j k}$ are:

$$
\begin{gathered}
A_{j k}=\sum_{i=1}^{3} K_{i} \frac{\frac{1}{L_{j k}}\left(\frac{S_{b}}{D^{*}}-b_{i}\right) \mathrm{e}^{-b_{i} H}+\beta_{j k}\left(\frac{S_{f}}{D^{*}}+b_{i}\right)}{\frac{1}{L_{j k}} \cdot \alpha_{j k}+\frac{S_{f}}{D^{*}} \cdot \beta_{j k}} \\
B_{j k}=\sum_{i=1}^{3} K_{i} \frac{\frac{S_{f}}{D^{*}}\left(\frac{S_{b}}{D^{*}}-b_{i}\right) \mathrm{e}^{-b_{i} H}-\alpha_{j k}\left(\frac{S_{f}}{D^{*}}+b_{i}\right)}{\frac{1}{L_{j k}} \cdot \alpha_{j k}+\frac{S_{f}}{D^{*}} \cdot \beta_{j k}}
\end{gathered}
$$

with

$$
\begin{aligned}
& \alpha_{j k}=\frac{1}{L_{j k}} \sinh \left(\frac{H}{L_{j k}}\right)+\frac{S_{b}}{D^{*}} \cosh \left(\frac{H}{L_{j k}}\right) \\
& \text { and } \beta_{j k}=\frac{1}{L_{j k}} \cosh \left(\frac{H}{L_{j k}}\right)+\frac{S_{b}}{D^{*}} \sinh \left(\frac{H}{L_{j k}}\right)
\end{aligned}
$$

The expressions of the coefficient $A_{j k}$ and $B_{j k}$ lead to the solution of Equation (1) and the introduction of Equation (11) in Equation (8) leads to the solution of the continuity equation.

\section{Results and Discussions}

\subsection{Solar Cell Base Overheating and Effect of Temperature on the Carriers Mobility}

In this work, we study the temperature effect on a silicon solar under intense light illumination. For a multispectral light illumination, an intensification of the illuminated light means an increase of the quantity of photons which crosses the illuminated side of the solar cell. The consequence of this situation will be an increase of the carriers photogeneration in the base and then an increase of the density of carriers. The increase of the density of carriers in the base of the solar cell leads none the less to an increase of the collision between excess minority carriers but also to an increase of the quantity of the energy released by thermalization [24] in the base of the solar cell. 
With the increase of the photogeneration due to the intensification of the illuminated light, another phenomenon which appears is the carriers concentration gradient electric field. His orientation is illustrated in Figure 1 and its expression is given by Equation (1). The expression of the electric field is inversely proportional to the carriers mobilities. Since the carriers mobility decrease with the increase of the temperature, consequently the electric field will increase with the increase of the temperature in the base of the solar cell. According to its orientation, it opposes to the movement of electrons toward the junction and to the move of holes to the rear side, and then has as effect to brake them. These braking releases also energy in the base of the solar cell and that contributes to heat the base of the solar cell. These three phenomena (energy released by thermalization, carriers collisions and carriers braking) lead to an increase of the heat in the base of the solar cell.

The expressions of carriers (electron and hole) mobility in function of the temperature are given in Equations (3) above. We present on the curves of Figure 2 and Figure 3, the effect of the increase of the temperature on the carriers mobility in the base of the solar cell.

It appears trough these curves that the carriers mobility decrease when the temperature in the base of solar cell increase. The decrease of carriers mobility is the consequence of two phenomena:

- the increase of carriers density with the increase of light intensity, which comes

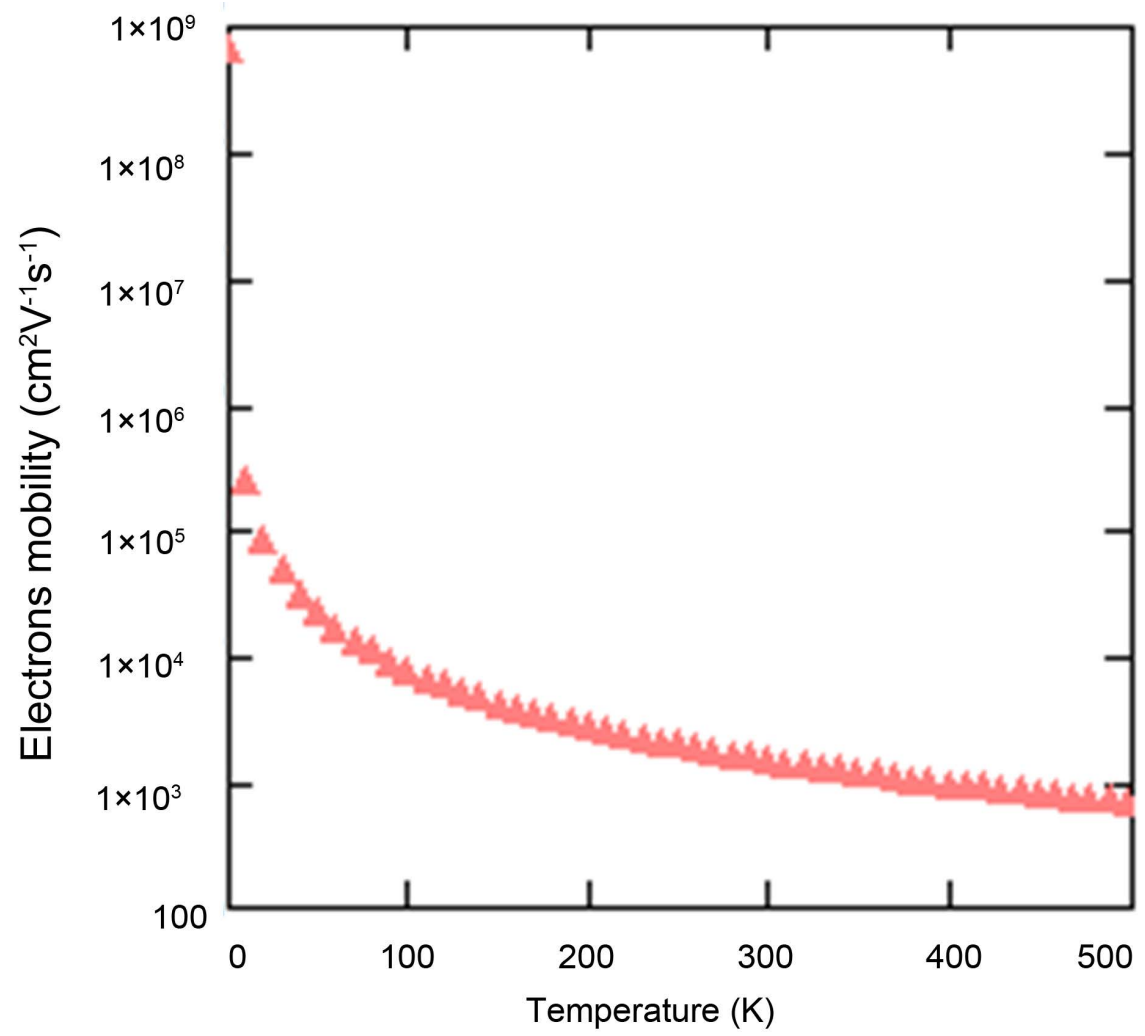

Figure 2. Influence of temperature on electrons mobility: $\mu_{0 n}=1500 \mathrm{~cm}^{2} / \mathrm{Vs} ; T_{0}=300 \mathrm{~K}$. 


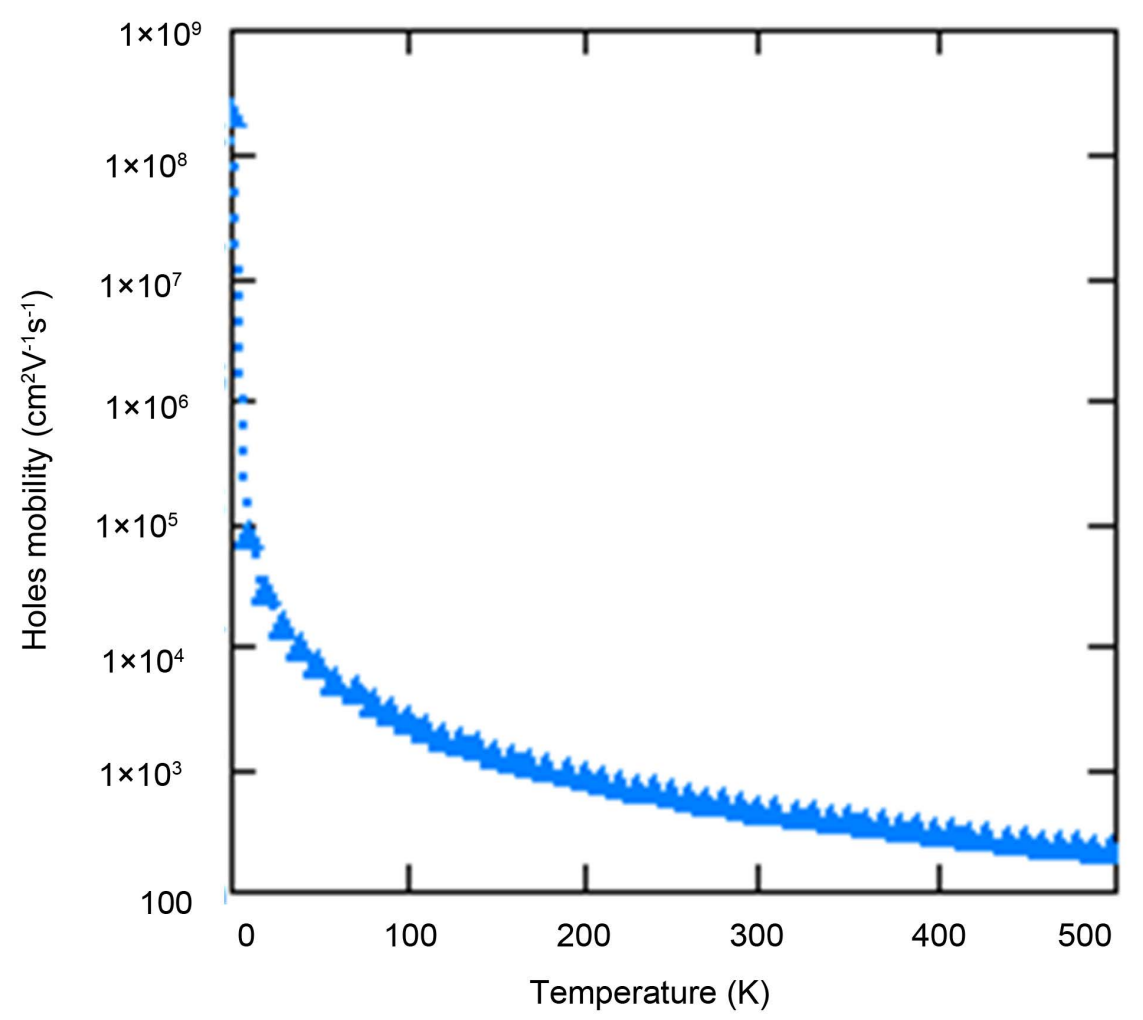

Figure 3. Influence of temperature on Holes mobility: $\mu_{0 p}=475 \mathrm{~cm}^{2} / \mathrm{Vs} ; T_{0}=300 \mathrm{~K}$.

with an intensification of carriers collision in the base and then carriers slowing down.

- the increase of carriers density leads also to an increase of the carriers concentration gradient electric field which is opposed to the carriers movement toward the junction and then brake them.

The carriers slowing down due to their collision and braking lead to the decrease of the carriers mobilities. But, since carriers collision and braking come with the increase of the temperature in the base of the solar cell (energy released by collision and braking) we have the impression that it is the increase of the temperature which is responsible of the carriers mobility decrease.

\subsection{Effect of the Temperature on the Diffusion Parameters of the Silicon Solar Cell}

The expressions of the diffusions coefficient of the silicon solar cell under an intense light illumination are given by Equation (7) and these expressions are functions of the electrons and holes mobility which are functions of the temperature. These coefficients are then functions of the temperature. We present on the curves of Figure 4 and Figure 5 below the effect of temperature on excess minority carrier diffusion coefficient and diffusion length.

We observe on the curves of Figure 4 and Figure 5 that the diffusion coefficient and the diffusion length decrease with the increase of the temperature in the base of the solar cell. Since the increase of the temperature is the consequence of 


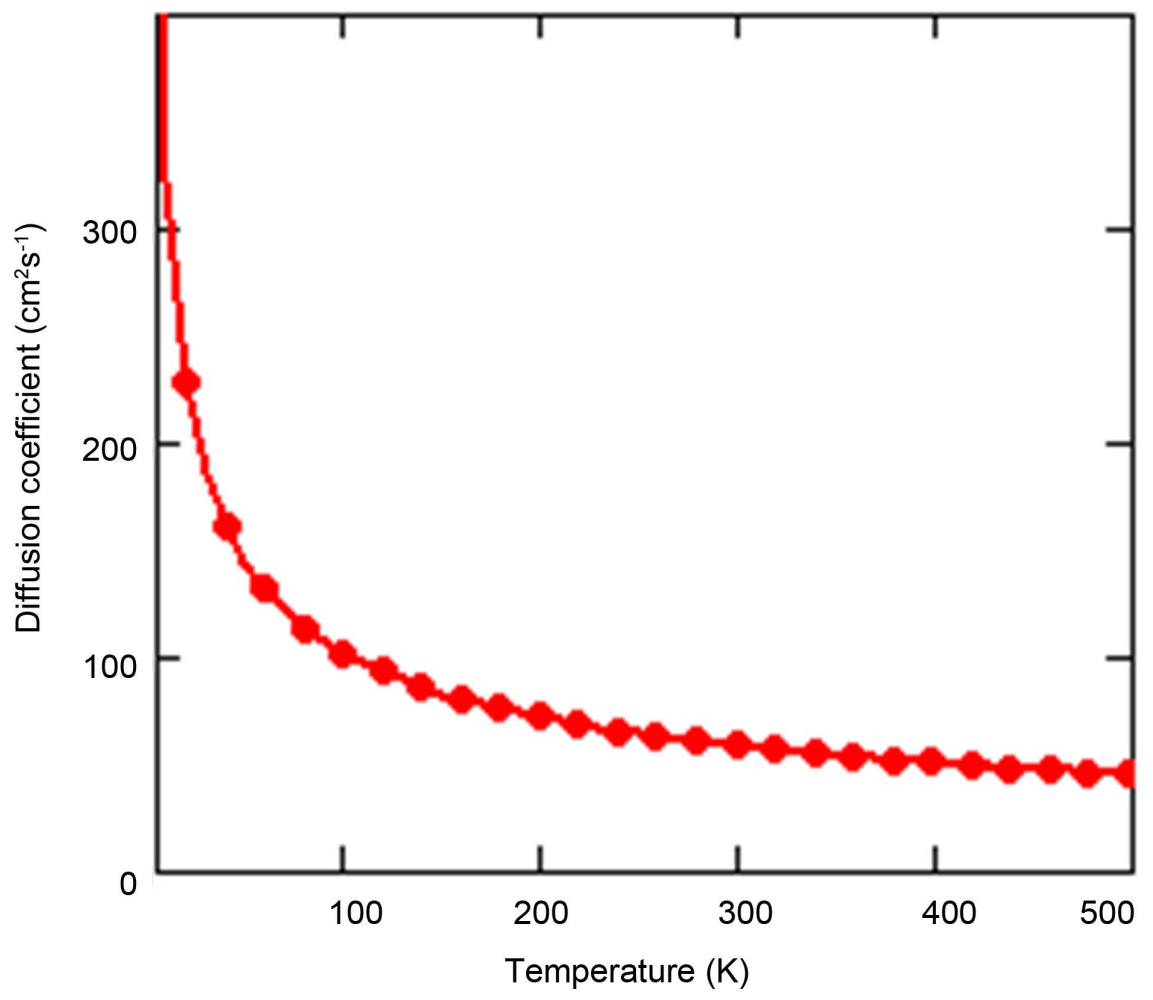

Figure 4. Influence of temperature on diffusion coefficient: $C=50$ suns, $D_{n}=26 \mathrm{~cm}^{2} \cdot \mathrm{s}^{-1}$; $D_{p}=4 \mathrm{~cm}^{2} / \mathrm{s} ; \mu_{0 n}=1500 \mathrm{~cm}^{2} / \mathrm{Vs} ; \mu_{0 p}=475 \mathrm{~cm}^{2} / \mathrm{Vs} ; L_{n}=0.02 \mathrm{~cm}$.

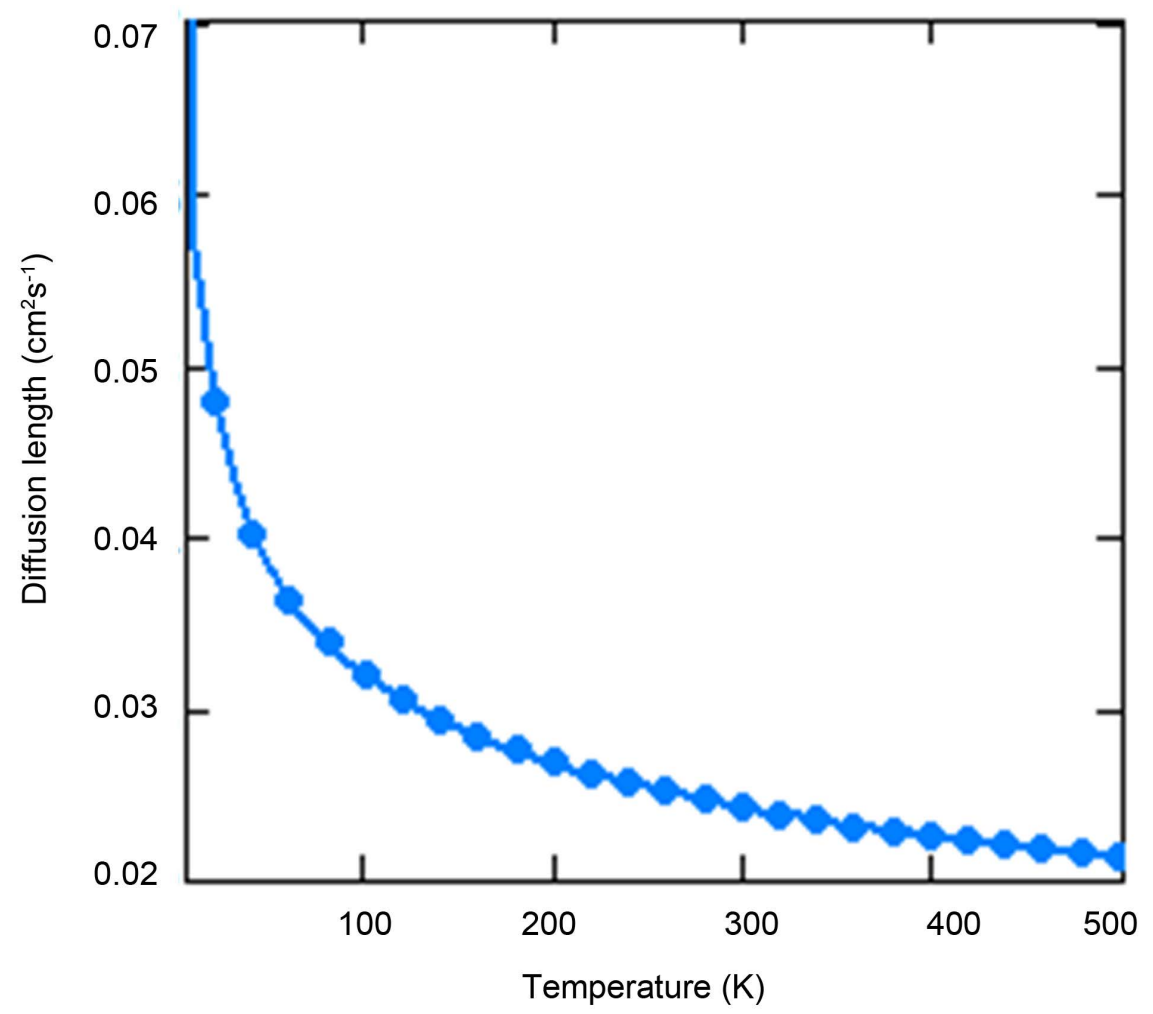

Figure 5. Influence of temperature on diffusion length: $C=50$ suns, $D_{n}=26 \mathrm{~cm}^{2} \cdot \mathrm{s}^{-1} ; D_{p}=$ $4 \mathrm{~cm}^{2} \cdot \mathrm{s}^{-1} ; \mu_{0 n}=1500 \mathrm{~cm}^{2} / \mathrm{Vs} ; \mu_{0 p}=475 \mathrm{~cm}^{2} / \mathrm{Vs} ; L_{n}=0.02 \mathrm{~cm}$. 
the increase of the carriers collision and braking, the decrease of the diffusion coefficients with the increase of the temperature mean also that the diffusion coefficients decreases when the carriers collision and braking increases. Indeed, the diffusion coefficient and the diffusion length are sensitive to any obstacle to the carrier movement in the base of solar cell. Then, the increase of collisions between carriers due to the increase of carriers density in the base and their slowing down due to the increase of carrier concentration gradient electric field lead to the decrease of the diffusion parameters.

\subsection{Effect of the Carriers Density on the Temperature of the Solar Cell Base}

Figure 6 and Figure 7 illustrate the effect of carriers density near the junction $(\mathrm{z}=0.005 \mathrm{~cm})$ on the behavior of the temperature of a silicon solar cell base for two operating state: short circuit operating state and open circuit operating state. For these two figures the light illumination intensity has been taken equal to 50 suns [13].

We observe on Figure 6 and Figure 7 that, near the junction $(z=0.005 \mathrm{~cm})$, the temperature in the base of the solar cell increase with the increase of the carriers density as well in short circuit operating mode than in open circuit operating

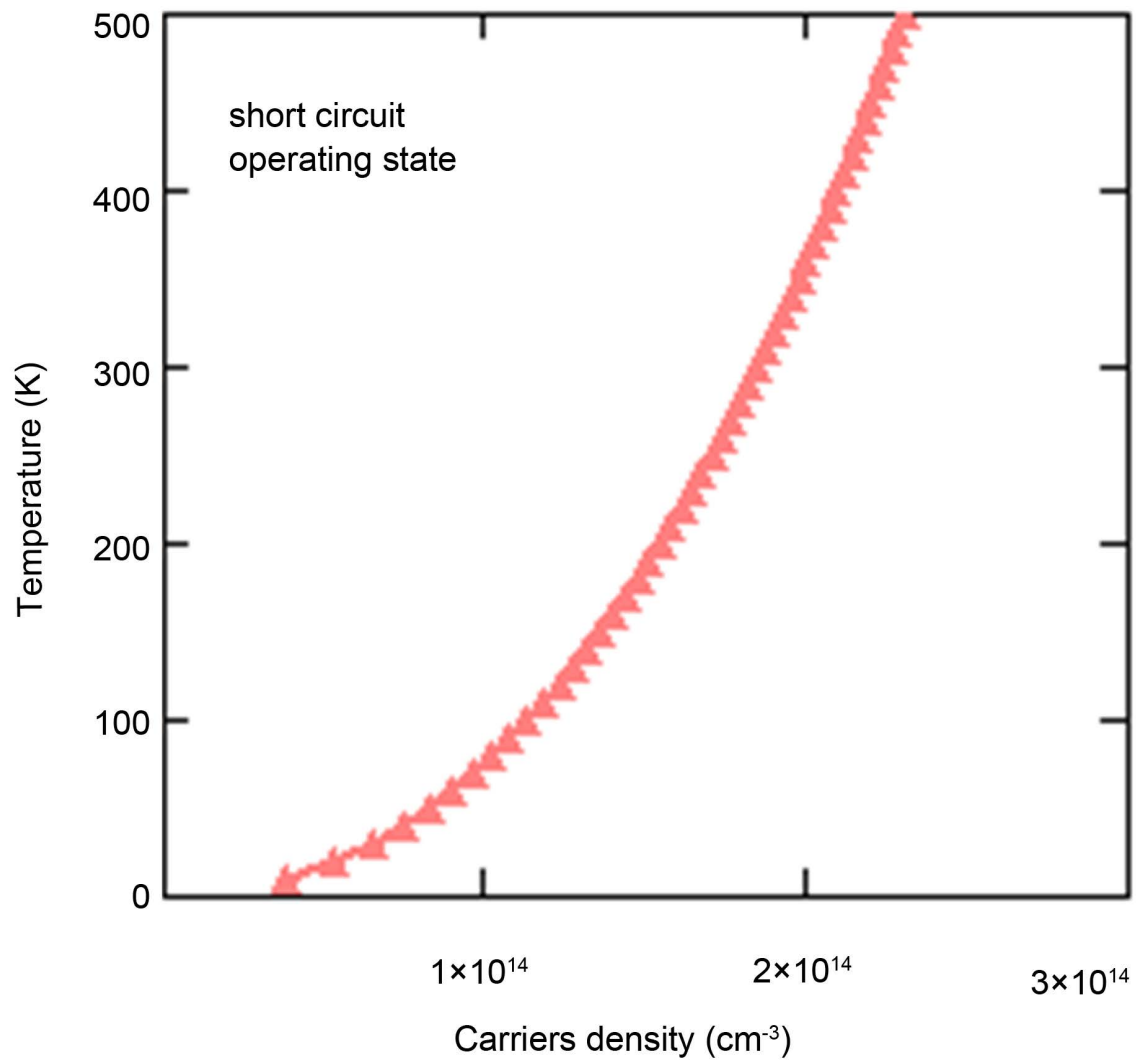

Figure 6. Effect of excess minority carriers density in short circuit operating state on the temperature of the base of the solar cell: $C=50$ suns, $D_{n}=26 \mathrm{~cm}^{2} \cdot \mathrm{s}^{-1} ; D_{p}=4 \mathrm{~cm}^{2} / \mathrm{s} ; L_{n}=$ $0.02 \mathrm{~cm} ; S_{g b}=10^{2} \mathrm{~cm} / \mathrm{s} ; S_{b}=10^{3} \mathrm{~cm} / \mathrm{s} ; H=0.03 \mathrm{~cm}$. 


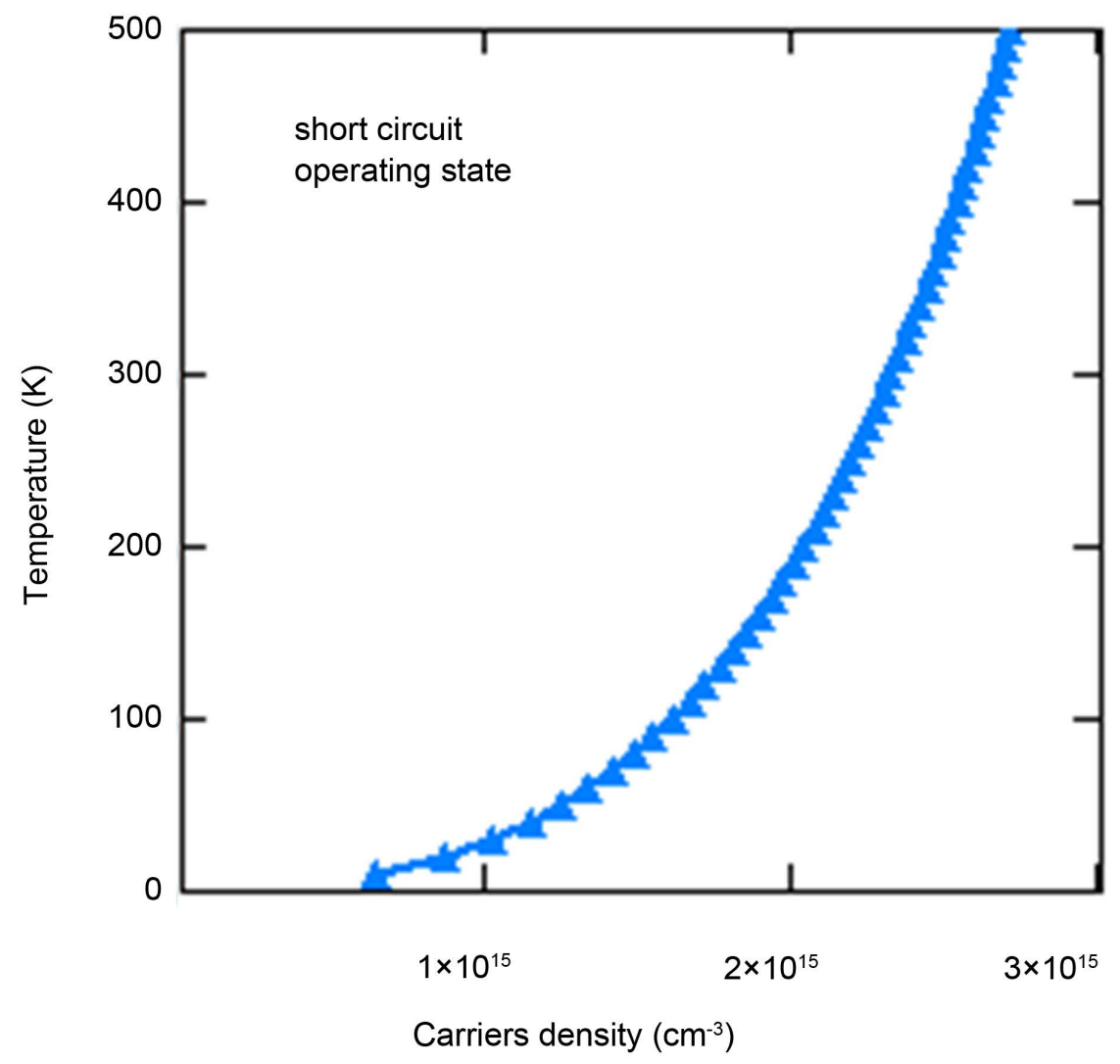

Figure 7. Effect of excess minority carriers density in open circuit operating state on the temperature the base of the solar cell: $C=50$ suns, $D_{n}=26 \mathrm{~cm}^{2} \cdot \mathrm{s}^{-1} ; D_{p}=4 \mathrm{~cm}^{2} / \mathrm{s} ; L_{n}=0.02$ $\mathrm{cm} ; S_{g b}=10^{2} \mathrm{~cm} / \mathrm{s} ; S_{b}=10^{3} \mathrm{~cm} / \mathrm{s} ; H=0.03 \mathrm{~cm}$.

mode. The increase of carriers density in the region near the junction means an increase of the quantity of carriers present in this region. The increase of the density of the carriers comes with the increase of collisions between carriers and the increase of the quantity of energy releases by thermalization in this region. The increase of carrier density leads also to increase of the carriers concentration gradient electric field and then the increase of the energy released by braking. The increase of the temperature in the base of the solar cell is then the consequence of the energy which have been released by collisions, thermalization and braking with the increase of carriers density. It appears also on these curves that for the same base heating temperature, the density of carriers which contribute in open circuit operating mode is higher than ones of short circuit operating mode. This observation is the consequence of the operating mode. In short circuit and open voltage operating modes, the energy release by collisions, thermalization and braking exist. But contrarily to the open circuit operating mode where the carriers are blocked, in short circuit operating mode, the maximum of carriers crosses the junction and then that reduces the presence of carriers near the junction.

The curves of Figure 8 illustrate the effect of carriers density near the junction on the behavior of the temperature of a silicon solar cell in intermediate operating 


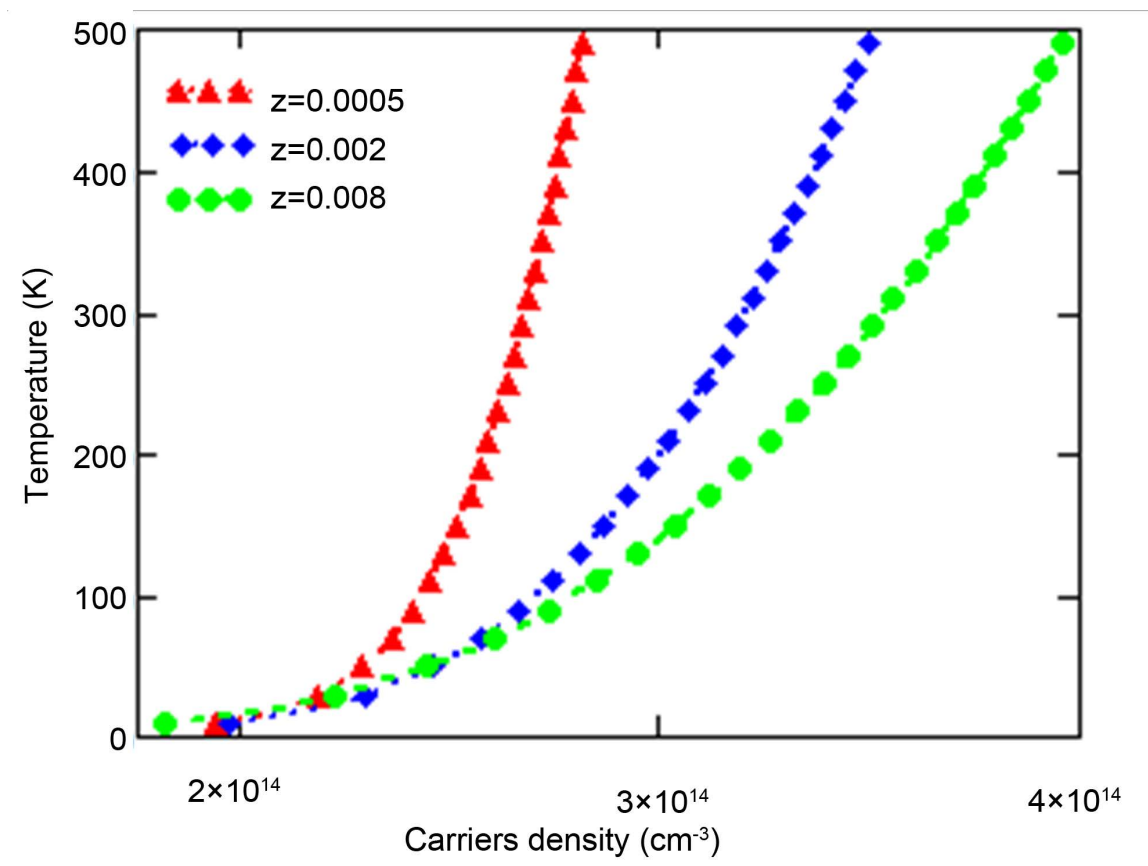

Figure 8. Effect of excess minority carriers density in intermediate operating state on the temperature of the base at tree levels of the base depth $C=50$ suns, $D_{n}=26 \mathrm{~cm}^{2} \cdot \mathrm{s}^{-1} ; D_{p}=$ $4 \mathrm{~cm}^{2} / \mathrm{s} ; L_{n}=0.02 \mathrm{~cm} ; S_{g b}=10^{2} \mathrm{~cm} / \mathrm{s} ; S_{b}=10^{3} \mathrm{~cm} / \mathrm{s} ; H=0.03 \mathrm{~cm}$.

state (junction recombination velocity $S_{f}=10^{4} \mathrm{~cm} / \mathrm{s}$ ). On the curves of Figure 8 , we illustrate for the illumination level ( $C=50$ Suns), the effect of carriers density on the behavior of the temperature at tree levels of the base depth.

It appears on the curves of Figure 8, that for a given value of carriers density, the temperature increases when we approach the junction. As shown in Figure 1, for a given illumination light, the carriers density and then the carriers concentration gradient electric field decreases from the junction toward the rear zone of the solar cell. Since the temperature increase effects are linked to the carriers concentration and braking, the increase of carriers concentration and carriers concentration gradient electric field near the junction lead to a higher increase of the temperature there. The small values of carries density near the junction are explained by the fact that the carriers photogenerated near the junction cross it to participate to the production of photocurrent.

\section{Conclusions}

In this work, we proposed a 3-D modeling study of the effects of the physical phenomena which contribute to heat the base of a solar cell and the effect of the temperature on the electronic parameters of a polycrystalline silicon solar cell under an intense light illumination. The resolution of the continuity equation leads to news expressions of carriers density, diffusion coefficient and diffusion length. It was proved through this study that, if the temperature in the base of the solar increases, the mobility of electrons and holes, the diffusion coefficient and the diffusion length decrease. The increase of the temperature is the consequence of 
the energy releases by thermalization in the base of the solar cell, the collision between carriers due to the high photogeneration and the carriers braking due to the carriers concentration gradient electric field. The study of the temperature effect on the electronic parameters of the solar cell, put in evidence that, with the intensification of the illumination, it is the collisions between carriers and their braking that are responsible of carriers mobility and diffusion parameters decrease. It appears also through this study that the temperature in the base of the solar cell increases with the increase of carriers concentration at short circuit, open circuit and intermediate operating points. This situation is also the consequence of electrons collision and carriers concentration gradient electric field increase with the increase of carriers density.

All these results characterize the fact that the effect of temperature on the electronic parameters of a solar cell is in reality the effect of carriers thermalization, the collision between carriers due to the high photogeneration and the carriers braking due to the carriers concentration gradient electric field.

\section{Acknowledgements}

The authors wish to thank International Science Program (ISP) for funding our research group and allowing to conduct these works.

\section{References}

[1] Dieye, M., Mbodji, S., Zoungrana, M., Zerbo, I., Dieng, B. and Sissoko, G. (2015) A 3D Modelling of Solar Cell's Electric Power under Real Operating Point. World Journal of Condensed Matter Physics, 5, 275-283. https://doi.org/10.4236/wjcmp.2015.54028

[2] Zerbo, I., Zoungrana, M., Seré, A.D., Ouedraogo, F., Sam, R., Zouma, B. and Zougmoré, F. (2011) Influence d'une onde électromagnétique sur une photopile au silicium sous éclairement multispectral en régime statique. Revue des Energies Renouvelables, 14, 517-532.

[3] Kolsi, S., Samet, H. and Amar, M.B. (2010) An Efficiency Optimization of a Polysilicon Photovoltaic Module Using a 2-D Analytical and a Two-Diode i-v Model for an Illuminated Solar Cell. Lebanese Science Journal, 11, 87-104.

[4] Nzonzolo, Lilonga-Boyenga, D. and Sissoko, G. (2014) Illumination Level Effects on Macroscopic Parameters of a Bifacial Solar Cell. Energy and Power Engineering, 6, 25-36. https://doi.org/10.4236/epe.2014.63004

[5] Khan, F., Singh, S.N. and Husain, M. (2010) Effect of Illumination Intensity on Cell Parameters of a Silicon Solar Cell. Solar Energy Materials \& Solar Cells, 94, 14731476. https://doi.org/10.1016/j.solmat.2010.03.018

[6] Barro, F.I., Sane, M. and Zouma, B. (2015) On the Capacitance of Crystalline Silicon Solar Cells in Steady State. Turkish Journal of Physics, 39, 122-127.

[7] Zoungrana, M., Zerbo, I, Ouédraogo, F., Zouma, B. and Zougmoré, F. (2012) 3D Modelling of Magnetic Field and Light Concentration Effects on a Bifacial Silicon Solar Cell Illuminated by Its Rear Side. IOP Conf. Series. Materials Science and Engineering, 29, 012020.

[8] El-Shaer, A., Tadros, M.T.Y. and Khalifa, M.A. (2014) Effect of Light Intensity and Temperature on Crystalline Silicon Solar Modules Parameters. International Journal of Emerging Technology and Advanced Engineering, 4, 311-318. 
[9] Erel, S. (2008) Comparing the Behaviors of Some Typical Solar Cells under External Effects. TEKNOLOJI, 11, 233-237.

[10] Zoungrana, M., Zerbo, I., Savadogo, M., Tendrebeogo, S., Soro, B. and Bathiebo, D.J. (2017) Effect of Light Intensity on the Performance of Silicon Solar Cell. Global Journal of Pure and Applied Sciences, 23, 123-129.

[11] Combari, D.U., Zerbo, I., Zoungrana, M., Ramde, E.W. and Bathiebo, D.J. (2017) Modelling Study of Magnetic Field Effect on the Performance of a Silicon Photovoltaic Module. Energy and Power Engineering, 9, 419-429.

[12] Zoungrana, M., Zerbo, I., Ouedraogo, F., Zouma, B. and Zougmoré, F. (2012) 3D Modelling of Magnetic Field and Light Concentration Effects on a Bifacial Silicon Solar Cell Illuminated by Its Rear Side. IOP Conference Series. Materials Science and Engineering, 29, 012020. https://doi.org/10.1088/1757-899X/29/1/012020

[13] Pelanchon, F., Sudre, C. and Moreau, Y. (1992) Solar cell under Intense Light Concentration: Numerical and Analytical Approaches. 11 th European Photovoltaic Solar Energy Conference, Montreux, 12-16 October 1992, 265-267.

[14] Agroui, K. (1999) Etude du comportement Thermique de Modules Phototvoltaiques de Technologie Monoverre et Biverre au silicium cristallin. Revue des Energies Renouvelables: Valorisation, 1, 7-11.

[15] Karki, I.B. (2015) Effect of Temperature on the I-V Characteristics of a Polycrystalline Solar Cell. Journal of Nepal Physical Society, 3, 35-40.

[16] Bouzid, F. and Ben Machich, S. (2010) The Effect of Solar Spectral Irradiance and Temperature on the Electrical Characteristics of a $\mathrm{ZnO}_{-}-\mathrm{SiO}_{2}-\mathrm{Si}(\mathrm{N})$ Photovoltaic Structure. Revue des Energies Renouvelables, 13, 283-294.

[17] Singh, P. and Ravindra, N.M. (2012) Temperature Dependence of Solar Cell Performance-An Analysis. Solar Energy Materials \& Solar Cells, 101, 36-45. https://doi.org/10.1016/j.solmat.2012.02.019

[18] Tobnaghi, D.M., Madatov, R. and Naderi, D. (2013) The Effect of Temperature on Electrical Parameters of Solar Cells. International Journal of Advanced Research in Electrical, Electronics and Instrumentation Engineering, 2, 6404-6407.

[19] O’Donnell, K.P. and Chen, X. (1991) Temperature Dependence of Semiconductor Band Gaps. Applied Physics Letters, 58, 2924. https://doi.org/10.1063/1.104723

[20] Zoungrana, M., Zerbo, I., Seré, A.D., Zouma, B. and Zougmoré, F. (2011) 3D Study of Bifacial Silicon Solar Cell Under Intense Light Concentration and Under External Constant Magnetic Field: Effect of Magnetic Field on Carriers Mobility and Carriers Density. Global Journal of Engineering Research, 10, 113-124.

[21] Zoungrana, M., Zerbo, I., Barro, F.I., Sam, R., Touré, F., Samb, M.L. and Zougmoré, F. (2011) Modélisation à 3-D de l'influence de la taille des grains et de la vitesse de recombinaison aux joints de grain sur une photopile au silicium polycristallin sous éclairement concentrée. Revues des Energies Renouvelables, 14, 649-664.

[22] Dugas, J. (1994) 3-D Modeling of a Reverse Cell Made with Improved Multicrystalline Silicon Wafer. Solar Energy Materials \& Solar Cells, 32, 71-88. https://doi.org/10.1016/0927-0248(94)90257-7

[23] Ba, B., Kane, M. and Sarr, J. (2003) Modeling Recombination Current in Polysilicon Solar Cell Grain Boundaries. Solar Energy Materials \& Solar Cells, 80, 143-154. https://doi.org/10.1016/S0927-0248(03)00139-9

[24] Equer, B. (1993) Energie solaire photovoltaïque: Physique et technologie de la conversion photovoltaïque. CNRS France, Volume 1, Ellipses, Paris. 
Submit or recommend next manuscript to SCIRP and we will provide best service for you:

Accepting pre-submission inquiries through Email, Facebook, LinkedIn, Twitter, etc. A wide selection of journals (inclusive of 9 subjects, more than 200 journals)

Providing 24-hour high-quality service

User-friendly online submission system

Fair and swift peer-review system

Efficient typesetting and proofreading procedure

Display of the result of downloads and visits, as well as the number of cited articles Maximum dissemination of your research work

Submit your manuscript at: http://papersubmission.scirp.org/

Or contact sgre@scirp.org 